\title{
Characterization of Laurel Fruit Oil from Madeira Island, Portugal
}

\author{
Paula C. Castilho ${ }^{a, *}$, Maria do Céu Costa ${ }^{a, b}$, Ana Rodrigues ${ }^{b}$, and Ana Partidário ${ }^{c}$ \\ ${ }^{a}$ Departamento de Química, Universidade da Madeira, Campus da Penteada, 9000-390 Funchal, Portugal, \\ and Departamentos de ${ }^{b}$ Tecnologia de Indústrias Químicas and ${ }^{c}$ Tecnologia de Indústrias \\ Alimentares, Instituto Nacional de Engenharia e Tecnologia Industrial (INETI), Lisboa, Portugal
}

\begin{abstract}
The fixed oil extracted from Laurus spp. fruit from Madeira Island, Portugal, is used in local traditional medicine for a wide variety of health complaints. Physical properties, density and refractive index, as well as the TAG FA composition, sterols, and waxes were determined. The oil was found to have an unusually high content of volatiles (ca. 10\%), with trans-ocimene and germacrene D predominating. Oleic (30\%) and linoleic $(20 \%)$ acids were the main unsaturated FA, whereas lauric $(18 \%)$ and palmitic (up to $22.5 \%$ ) acids were the main saturated FA in the neutral lipid fraction. The oil had a sterol content on the same order as olive oil, with $\beta$-sitosterol (84\%) predominating. Two sesquiterpene lactones, dehydrocostuslactone and costunolide, accounted for $5 \%$ of the overall composition. Madeira laurel oil is not currently used as an edible oil because of its very strong flavor. Its claimed medicinal properties have not yet been validated, and this is the first report on the characterization of the commercial product.
\end{abstract}

Paper no. J11122 in JAOCS 82, 863-868 (December 2005).

KEY WORDS: Fatty acids, fruit oil, FTIR, GC-MS, Laurus spp., Madeira laurel oil.

The vast majority of plant preparations for internal or external use in phytotherapy are formulated as powders, tablets, capsules, infusions, decoctions, tinctures, or poultices. Essential oils are also common as herbal medicines, but very few preparations are available in which the fixed oil is an active component.

Alvarez and Rodriguez (1) presented an extended review of the vegetable oils currently used as excipients in cosmetics and medicine. Eight oils were the subject of monographs in the $E u$ ropean Pharmacopoeia (2), mostly referring to their application in dietetics and cosmetic formulations, dietary products, and parenteral preparations.

Some therapeutic oils described in the literature are already available on the market. These include evening primrose, flax, grapeseed, and borage oils as sources of PUFA, namely, linoleic and linolenic acids. These oils are recommended for the treatment of various health ailments. EFA supplementation has been shown to be very promising in a number of health areas, including reducing the risk factors of cardiovascular disease (e.g., high levels of blood LDL cholesterol, high blood pressure, and high levels of blood TG); preventing diabetes, rheumatoid arthritis

\footnotetext{
*To whom correspondence should be addressed at Centro de Química da Madeira, Universidade da Madeira, Campus Universitário da Penteada, 9000-390 Funchal, Portugal. E-mail: castilho@uma.pt
}

(3), skin conditions such as eczema and psoriasis, and mental disorders and brain functions (4,5); and as adjuvant in infant development (6). Other available and widely used oily preparations are wheat germ oil, usually considered a food supplement, and saw palmetto lipidosterol extract, which is used in the treatment of benign prostatic hyperplasia.

Madeira laurel oil is one of the few oily preparations. Although its claimed clinical properties still remain largely scientifically unproven and its use is mainly local, interest in the oil is spreading through the influence of emigrant communities.

For centuries, the oil expressed from the ripe fruit of Laurus novocanariensis (the Laurus subspecies found in the Madeira archipelagoes) has been used in traditional medicine, and was first mentioned in Draggendorf's medicinal plant encyclopedia as early as 1898. Recorded uses include its external application as an anti-infectious skin preparation, antirheumatic, and vulnerary; its intake as a blood depurative, stomachic, haemostatic; and its use for aploplexy and constipation (7).

Laurus nobilis fat also has some therapeutic uses, although its properties have been little documented $(8,9)$.

Today, in rural areas, Madeira laurel oil is sold directly by producers and in local general stores, whereas in the urban centers it is available from pharmacies and health-products shops.

Like olive oil, Madeira laurel oil is a "natural fruit juice" in the sense that both are obtained from the fruit of a tree solely by mechanical processes. The berries of L. novocanariensis are similar in aspect to wild olives, and the oil is extracted from them according to procedures quite similar to primitive olive oil production. Originally, it was mechanically extracted and percolated at room temperature; however, because of increasing demand coupled with protective legal restrictions, from which the botanical species have been benefiting, the oil is now produced by boiling the berries in water before crushing and pressing. This method affords a higher yield, although it increases the risk of reducing the aroma.

The leaves of the L. novocanariensis tree have been the subject of a few studies (10-13); however, the properties of the medicinal oil remain unknown. The aim of the present work is to characterize this traditional medicinal oil.

\section{EXPERIMENTAL PROCEDURES}

Plant material. Laurel oil samples were obtained from local producers; production was monitored from the collection of the laurel berries. Some determinations were performed on the 
total oil; fractionation by different methods was used to separate the various families of compounds and thus facilitate analysis of the oil. Olive and sunflower oils were purchased from a local supermarket. For comparative studies, L. nobilis fat was obtained by crushing and pressing ripe berries collected in Alenquer, Portugal.

Oils were fractionated into the essential oil (OE), a lipid fraction (LF), and a methanol fraction (MF) by hydrodistillation and liquid-liquid partition as described previously (14). Briefly, hydrodistillation was performed on $50 \mathrm{~g}$ portions of laurel oil until exhaustion, yielding $c a .5 \mathrm{~g}$ of $\mathrm{OE}$ and an odorless residue containing the lipids and nonvolatile minor compounds. The residue was dissolved in $n$-hexane and filtered through activated charcoal to remove the chlorophylls. The filtrate was extracted with four $20 \mathrm{~mL}$ portions of methanol. The fraction insoluble in methanol was called the LF.

The methanol extracts were concentrated in a rotary evaporator, redissolved in $10 \mathrm{~mL}$ of acetonitrile, and defatted with 3 $\times 10 \mathrm{~mL}$ of hexane. The acetonitrile was evaporated under vacuum at room temperature and the residue ( $2.6 \mathrm{~g})$ was taken up with $1 \mathrm{~mL}$ of methanol (MF).

Determination of physical characteristics. The methods used for the determination of density and refractive index were adapted from AOAC Method 969.18: 1990 (15). The refractive index was measured at $25^{\circ} \mathrm{C}$ using an Abbé refractometer (ATAGO RX-1000); the density was also determined at $25^{\circ} \mathrm{C}$ using a $10 \mathrm{~cm}^{3}$ pycnometer. For both methods, water was used as a reference material.

Spectrophotometric measurements on the UV and visible region were performed according to the following procedure: Each oil sample of $250 \mathrm{mg}$ was placed in a $25 \mathrm{~mL}$ graduated flask and dissolved in cyclohexane (spectrophotometric grade) up to the mark and homogenized in a vortex; UV/vis spectra $(1000-190 \mathrm{~nm})$ were recorded in a Perkin-Elmer Lambda 2 instrument, at $25 \pm 0.1{ }^{\circ} \mathrm{C}$, using pure solvent as the blank and 1 $\mathrm{cm}$ optical-length quartz cuvettes.

FTIR. IR analysis was performed using a Nicolet Avatar 360 instrument equipped with a DTGS detector, Ever-Glow ${ }^{\mathrm{TM}}$ midIR source, and $\mathrm{KBr}$ beamsplitter, and interfaced with a Pentium III personal computer running Windows-based Nicolet OMNIC E.S.P.5.1 software (Thermo Electron Corporation, Waltham, MA). The instrument was purged with dry nitrogen (>99.9\%) during the transmission analysis to minimize the interference of water and carbon dioxide.

A small amount of oil sample was deposited between two $\mathrm{KBr}$ disks separated by a $15 \mu \mathrm{m}$ Teflon spacer. The $\mathrm{KBr}$ disks were polished daily. Transmission spectra were recorded in the $4000-400 \mathrm{~cm}^{-1}$ spectral range, with a resolution of $2 \mathrm{~cm}^{-1}$, in autogain. For each spectrum, 32 interferograms were co-added before Fourier transformation. Spectra are presented in the absorbance mode.

Analytical determinations. In general, for the characterization of laurel oil with respect to FA composition, sterols, and waxes, the European Community regulations for olive oil were followed (16-19). Because of the specific characteristics of laurel oil, these procedures were adapted for some determinations.
FA. FA were determined according to ISO Standard 5508:1996 and ISO Standard 5509:2000. Oil (500 mg) was accurately weighed into a screw-capped tube, and $3 \mathrm{~mL}$ of isooctane was added and mixed until the oil was totally dissolved. Transmethylation was performed with $2 \mathrm{~mL}$ of a methanolic sodium hydroxide solution $(2 \mathrm{~N})$. The tube was capped and shaken for $30 \mathrm{~s}$. The aqueous and organic layers were then allowed to separate, and $2 \mu \mathrm{L}$ from the top (iso-octane) layer was injected into the gas chromatograph.

The analysis of FAME was performed on a Trace 2000 Thermo Quest CE gas chromatograph, with a split/splitless injector and a FID. The analytical column was a DB-23 fusedsilica capillary column, with $60 \mathrm{~m} \times 0.25 \mathrm{~mm}$ i.d. and $0.25 \mu \mathrm{m}$ film thickness (J\&W Scientific, Folsom, CA). The temperature program was raised from 70 to $195^{\circ} \mathrm{C}$ at $5^{\circ} \mathrm{C} \mathrm{min}{ }^{-1}$, held for $10 \mathrm{~min}$, and then raised to $220^{\circ} \mathrm{C}$ at $5^{\circ} \mathrm{C} \mathrm{min}^{-1}$, and held at that temperature for another $30 \mathrm{~min}$. The injector and detector temperatures were set at 220 and $280^{\circ} \mathrm{C}$, respectively. The sample injection volume was $2 \mu \mathrm{L}$. The carrier gas was helium at a pressure of $70 \mathrm{kPa}$. Quantification was achieved by internal normalization. Correction factors calculated for this column and equipment were used to convert area percentages into mass percentages; correction factors were determined by the analysis of reference materials certified by the Bureau Communitaire de Reference in Brussels, Belgium.

Since laurel oil is rich in lipid-soluble compounds that are also soluble in iso-octane, the GC analysis was confirmed by GC-MS in order to identify several peaks that did not have a match in the standard FA mixtures.

A Trace 2000 GCQ system composed of a gas chromatograph coupled with a mass spectrometer was used. The compound mixture was separated on a fused-silica capillary column (DB-23, $60 \mathrm{~m} \times 0.25 \mathrm{~mm} \times 0.25 \mathrm{~mm}$ film thickness; J\&W Scientific), with a temperature program ramped from 70 (held $1 \mathrm{~min}$ ) to $200^{\circ} \mathrm{C}$ (held $15 \mathrm{~min}$ ) at a rate of $3^{\circ} \mathrm{C} \mathrm{min}^{-1}$. The injector temperature was $250^{\circ} \mathrm{C}$. Injection was carried out in split mode at $30 \mathrm{~mL} / \mathrm{min}$, and the carrier gas (helium) pressure was maintained at $200 \mathrm{kPa}$. The interface (keeping the capillary column end in the ion source block) was maintained at $220^{\circ} \mathrm{C}$. The ion trap mass spectrometer operated at an electron energy of $70 \mathrm{eV}$, an electron emission of $300 \mathrm{~mA}$, an ion source temperature of $200^{\circ} \mathrm{C}$, and an analyzer temperature of $100^{\circ} \mathrm{C}$.

Sterols. The sterol contents of the samples were determined qualitatively and quantitatively according to the European Official Methods of Analysis, described in Regulations EEC/2568/91 and EEC/1429/92 of the European Union Commission (16-18), and standardized by ISO Standard 12228:1999. The determinations gave sterol results, expressed in $\mathrm{mg} / \mathrm{kg}$ of fat material, total sterols, and individual sterols.

$G C$. For sterols quantification, the chromatograph was a Perkin-Elmer 8600 with an FID detector, equipped with an HP 6890 integrator. The column was a Thermo Bond SF-52 (25 m $\times 32 \mathrm{~mm} \times 0.25 \mathrm{~mm}$; Thermo Electron Corporation), and the split ratio was 1:50. Hydrogen was used as the carrier gas at a flow rate of $50 \mathrm{~cm} / \mathrm{s}$. The temperatures were: oven $260^{\circ} \mathrm{C}$, injector $280^{\circ} \mathrm{C}$, and detector $300^{\circ} \mathrm{C}$. 
TABLE 1

Relative Densities and Refractive Indices of Representative Samples and Fractions

\begin{tabular}{lcc}
\hline Sample & Relative density $\left(25^{\circ} \mathrm{C}\right)$ & Refractive index \\
\hline Laurel oil $^{a}$ & $0.8694 \pm 0.01$ & $1.4784 \pm 0.001$ \\
Laurel essential oil & $0.8460 \pm 0.01$ & $1.4952 \pm 0.001$ \\
Nonlipid residue & $0.8898 \pm 0.01$ & $1.4739 \pm 0.001$ \\
Laurel lipid fraction & $0.8907 \pm 0.01$ & $1.4675 \pm 0.001$ \\
Olive oil $^{a}$ & $0.9020 \pm 0.01$ & $1.4678 \pm 0.001$ \\
Sunflower oil $^{a}$ & $0.9211 \pm 0.01$ & $1.4730 \pm 0.001$ \\
\hline
\end{tabular}

${ }^{a}$ Commercial samples.

Waxes. The European Union Commission method of regulation EEC/183/93 (18) describes a procedure for determining the wax content of fats and oils under the test conditions. It is used in particular to distinguish between olive oil obtained by pressing and that obtained by solvent extraction (olive pomace oil). GC was performed using the same Perkin-Elmer 8600 equipment with an SGL-5 capillary column $(25 \mathrm{~m} \times 32 \mathrm{~mm} \times 0.25$ $\mu \mathrm{m}$; Supelco Inc., Bellefonte, PA). The operating conditions were as follows: column temperature: beginning at $80^{\circ} \mathrm{C}$, increasing by $30^{\circ} \mathrm{C} / \mathrm{min}$ to $120^{\circ} \mathrm{C}$, and then by $5^{\circ} \mathrm{C} / \mathrm{min}$ up to $340^{\circ} \mathrm{C}$; detector temperature: $350^{\circ} \mathrm{C}$; linear speed of the carrier gas (helium): $20-35 \mathrm{~mL} / \mathrm{s}$; amount injected: $1 \mu \mathrm{L}$ of the solution.

\section{RESULTS AND DISCUSSION}

Physical characterization. The physical parameters are shown in Table 1. Laurel oil is a dark green oil with a chlorophyll content superior to that of extra virgin olive oil. These chlorophylls are easily removed by filtration through activated charcoal. The color ratio $\mathrm{A}_{446} / \mathrm{A}_{668}$ (between carotenoids and chlorophylls) was determined directly on the oil according to the method of Papaseit (20). For olive oil, this parameter is always greater than 2.5, whereas for laurel oil it was 1.46.

The relative density, or specific gravity, compared with water at $25^{\circ} \mathrm{C}$ was $0.8694 \pm 0.001$ for genuine oils and 0.8966 \pm 0.009 for those considered adulterated. The density of an oil is known to increase as the mean molecular weight diminishes and also as the degree of unsaturation increases. In the present case, the low density of laurel oil (lower than that of current edible oils) may be due to its relative high saturation and to the high composition of low-density volatiles; the relative density of the OE obtained by hydrodistillation and determined under the same conditions was $d^{25}=0.8460 \pm 0.01$.

The refractive indices of natural fats and oils are related to their average degree of unsaturation in an approximately linear way, and they tend to increase with the number of double bonds (21). The refractive indices obtained for laurel oil samples were higher than those found in the literature for olive oil (1.4677-1.4705) and other vegetable oils. Although sunflower oil is more unsaturated, even this oil has a lower refractive index at the same temperature. This may again be due to the presence of volatile components rather than to variations in the degree of saturation. The OE hydrodistilled from laurel oil had an even higher refractive index. Both the distillation residue and the LF showed lower values for this physical parameter, closer to the values found for olive and sunflower oils.

FA composition. Table 2 presents the FA composition of laurel oils from different producers in Madeira, as well as the composition of commercial oils analyzed under identical conditions, and of $L$. nobilis L. fat extracted in our laboratory.

As in olive oil, oleic acid is the most abundant unsaturated FA found in Madeira laurel oil. However, laurel oil contains much higher percentages of saturated FA, with a higher degree of variation than the unsaturated FA. The characterization of TAG in the LF of Madeira laurel oil was recently published by our group (14). However, the lauric acid content was much lower than in L. nobilis (bay) fat. According to Garnier et al. (22), bay fat is composed of $48.1 \%$ lauric acid, $32.3 \%$ oleic acid, $6.2 \%$ palmitic acid, and $18.4 \%$ linoleic acid. More recent studies (23) on Turkish laurel berry fat have confirmed the existence of 20 FA, of which $54.2 \%$ were lauric acid, $15.1 \%$ oleic acid, and

TABLE 2

FA Composition (\%) of Selected Oils ${ }^{a}$

\begin{tabular}{lrrrrrr}
\hline FA & L1 & \multicolumn{1}{c}{ L2 } & L3 & Olive $^{b}$ & Sunflower $^{b}$ & Laurus nobilis $^{c}$ \\
\hline Capric (C10:0) & ND & ND & ND & ND & ND & 1.3 \\
Lauric (C12:0) & 18.6 & 16.4 & 14.0 & ND & ND & 30.0 \\
Myristic (C14:0) & 0.7 & 0.7 & 1.9 & ND & 0.1 & 0.8 \\
Palmitic (C16:0) & 20.8 & 19.3 & 22.5 & 10.7 & 6.7 & 14.7 \\
Palmitoleic (C16:1) & 0.4 & 0.4 & 0.7 & 0.8 & 0.1 & 0.2 \\
Stearic (C18:0) & 1.1 & 1.1 & 1.4 & 3.6 & 3.8 & 0.8 \\
Oleic (C18:1) & 32.6 & 31.6 & 32.8 & 76.2 & 28.9 & 22.1 \\
C18:1 trans & ND & ND & ND & ND & ND & 1.0 \\
Linoleic (C18:2) & 23.5 & 22.1 & 22.3 & 5.2 & 57.9 & 25.6 \\
Linolenic (C18:3) & 1.3 & 1.1 & 1.3 & 0.6 & 0.2 & 1.1 \\
Eicosenoic (C20:1) & 0.5 & 0.5 & 0.5 & 0.2 & 0.1 & 0.5 \\
& & & & & & \\
Total & 99.5 & 99.7 & 97.4 & 97.3 & 97.8 & 98.1 \\
$\Sigma$ saturated & 41.2 & 40.2 & 39.8 & 14.3 & 10.6 & 47.6 \\
$\Sigma$ unsaturated & 58.3 & 59.5 & 57.6 & 83.0 & 87.2 & 50.5 \\
\hline
\end{tabular}

${ }^{a} \mathrm{~L} 1, \mathrm{~L} 2$, and $\mathrm{L} 3$ are Madeira laurel oil samples from different producers. ND, not detected.

${ }^{b}$ Commercial dietary oil samples.

${ }^{c}$ Fixed oil freshly prepared from $L$. nobilis fruit. 


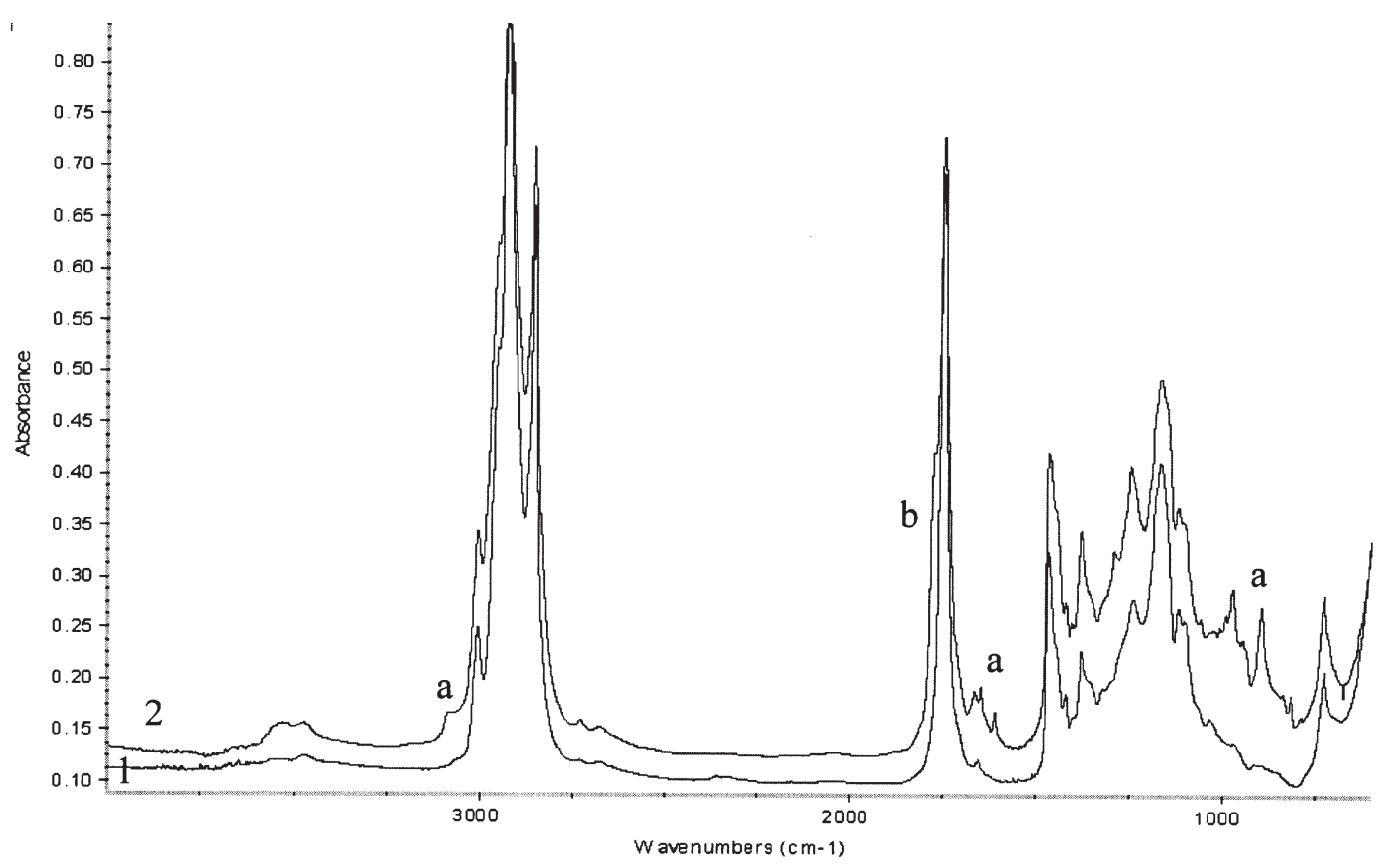

FIG. 1. Bands a (trans-ocimene) and $\mathbf{b}$ (lactones) in the total oil (line 2) are absent in the spectrum of the lipidic fraction (line 1).

17.2\% linoleic acid. Frega et al. (24) studied the lipid composition of several parts of $L$. nobilis berries and concluded that lauric acid resides mainly in the endocarp.

FTIR. Figure 1 shows the spectrum of laurel oil (between 4000 and $400 \mathrm{~cm}^{-1}$ ) and the spectrum of the LF; the two spectra were registered under the same conditions.

The mid-IR spectra of most seed oils and of the various grades of olive oil are superficially similar, since most vegetable oils contain the same FA (mainly 16 and 18 carbon atoms) and their TAG contents are also nearly identical. Generally, vegetable oils are $95-98 \%$ fat $(25,26)$. Subtle dissimilarities between the spectra do exist because of differences in the structure of the polymethylene chains, and considerable information can be extracted from the spectra. Commercially available seed and olive oils show strong resemblances with the LF of laurel oil.

The spectrum of the total laurel oil is much more complex than that of other edible and medicinal oils, since the so-called "minor" constituents (usually 2-5\%), including hydrocarbons, sterols, waxes, vitamins, and volatiles, account for more than $15 \%$ of the laurel oil. The bands attributable to the volatile fraction were the most significant of the nonlipid signals.

At this stage of our work, mid-FTIR analysis was used mainly to select genuine laurel oil samples from those adulterated with sunflower or soybean oil, on the basis of the relative intensity of a small group of IR bands. Particularly relevant were the bands that did not interfere with lipid absorbances; these included the characteristic out-of-plane $\mathrm{C}-\mathrm{H}$ bending vibrations at 989 and $890 \mathrm{~cm}^{-1}$, assigned to acyclic compounds in $\mathrm{OE}$; the stretching vibrations of double bonds conjugated with terminal methylene at 1639 and $1606 \mathrm{~cm}^{-1}$; and the char- acteristic weak $\mathrm{CH}$ stretching of $=\mathrm{CH}_{2}$ at $3080 \mathrm{~cm}^{-1}$ (26).

All these bands were also found in the IR spectrum of the OE distilled from laurel fruit and from the fixed fatty oil, and they are in good agreement with the GC analysis of this volatile fraction, which revealed trans-ocimene as its major component. These results were confirmed by FAME analysis.

Although not completely resolved in the IR spectrum, two bands at 1763 and $1768 \mathrm{~cm}^{-1}$ could be obtained by spectrum deconvolution; these perfectly matched the $\mathrm{C}=\mathrm{O}$ stretching bands of the two sesquiterpene lactones costunolide and dehydrocostuslactone isolated by column chromatography from the MF. In qualitative studies, FTIR has the advantage of being much faster (a couple of minutes) and requires less sample (1 drop) than FAME chromatographic analysis.

Sterols. Reported phytosterol data have shown that nuts and oils contain higher levels of sterols $(>1 \%)$ than do fruits and vegetables (27). Moreover, the compositional distributions of phytosterols in certain vegetable oils have been used for their identification, despite their presence as minor constituents. According to Aparicio and Aparacio-Ruýz (25), the profile of sterols is almost decisive in oil identification. The sterol marker in rapeseed oil is brassicasterol $(100-1100 \mathrm{mg} / \mathrm{kg}$ ), which is generally not detected in seed or pulp oils, whereas olive oil is characterized by $\beta$-sitosterol $(680-2610 \mathrm{mg} / \mathrm{kg})$ and $\Delta^{5}$ avenosterol (34-266 mg/kg) as the predominant sterols, and sunflower oil is identified by the presence of relatively high levels of $\Delta^{7}$-avenosterol (150-500 mg/kg). Verleyen et al. (27) proposed a classification of vegetable oils in terms of their sterol contents as high-, medium-, and low-sterol oils. The first category would include corn oil (7796-9680 mg/kg), avocado seed oil (reported 10,000 mg/kg), commodity rapeseed oil 
$(7670-8238 \mathrm{mg} / \mathrm{kg}$ ), and rice bran oil (where sterols may reach $11,900 \mathrm{mg} / \mathrm{kg}$ ). Medium-sterol oils would be soybean (2670-3013 mg/kg), sunflower (2946-3832 mg/kg), peanut (about $2287 \mathrm{mg} / \mathrm{kg}$ ), and olive oil, for which wide variation (ranging from 876 to $2210 \mathrm{mg} / \mathrm{kg}$ ) in the total sterol contents has been reported. Low-sterol oils would include walnut oil (about $1440 \mathrm{mg} / \mathrm{kg}$ ), palm oil (599-794 mg/kg), and coconut oil (689 mg/kg).

Results are strongly dependent on the sterol isolation techniques used; therefore, only data obtained using the saponification/silylation method (European Official Method of Analysis) or an equivalent were taken into consideration.

Table 3 presents the sterol composition of a Madeira laurel oil and compares that composition with values reported for olive oil obtained by the same method. The laurel oil analyzed, with a total sterol content of $2164 \mathrm{mg} / \mathrm{kg}$, may be considered a mediumsterol oil. $\beta$-Sitosterol accounts for $84 \%$ of the total sterols, campesterol for $7.5 \%$, and $\Delta^{5}$-avenosterol for $3.8 \%$. This composition is within the limits usually found in olive oils.

The sterol composition of olives and olive oils is known to vary with the cultivar, fruit ripening at the time of harvest, fruit storage, and oil storage. For the purpose of the present study, those parameters were not taken into consideration. The laurel oil sample under scrutiny for sterols was produced less than 3 mon prior to analysis, from ripe berries recently picked from laurel trees, which for centuries have grown wild in a very confined space on a small island.

Waxes. Laurel oil is richer in waxes than extra virgin olive oil. There is an equilibrium between short- and long-chain waxes $\left(\mathrm{C}_{36}+\mathrm{C}_{38}=139, \mathrm{C}_{40}+\mathrm{C}_{42}+\mathrm{C}_{44}+\mathrm{C}_{46}=141\right)$, whereas olive oil usually has larger amounts of short-chain waxes. This
TABLE 3

Sterol Composition

\begin{tabular}{lcc}
\hline Sterol $(\mathrm{mg} / \mathrm{kg})$ & Laurel oil $(\mathrm{L} 2)^{a}$ & Olive oil $^{b}$ \\
\hline Cholesterol & 10.0 & 1.76 \\
2,4-Methylenecholesterol & 2.1 & 3.76 \\
Campesterol & 162 & 49.8 \\
Campestanol & 6.7 & 6.13 \\
Stigmaterol & 16.9 & 10.2 \\
Clerosterol & 27.7 & 16.5 \\
Sitosterol & 1818 & 1511 \\
Sitostanol & 14.5 & 9.90 \\
$\Delta 5$-Avenosterol & 80.5 & 98.3 \\
$\Delta 7-S t i g m a t e r o l$ & $\mathrm{ND}$ & 5.90 \\
$\Delta 7-$ Avenosterol & $\mathrm{ND}$ & 5.26 \\
Eritrodiol & 10.0 & $\mathrm{ND}$ \\
Total & 2164 & 1724
\end{tabular}

${ }^{a}$ For abbreviations see Table 2.

${ }^{b}$ Commercial sample.

phenomenon suggests that these substances, which are present in the external cuticle of the fruit, were in large part carried away by the percolated oil. The surface lipid layer, which is also present in olive fruit and leaves (28), is believed to be important for chemotaxonomic purposes and could play a role in determining the resistance of the tree to biotic or abiotic stresses. This may be a very useful line of research to help differentiate taxa and in species conservation.

$O E$. The most significant characteristic of this berry oil is its high content of volatiles. Whereas the volatile contents in olive and other edible oils are very low, and bay (L. nobilis) fat has about a 3\% volatile fraction, the hydrodistillation of Madeira laurel oil gave more than $10 \%$ of OE extract, in which trans- $\beta$ ocimene was the major monoterpene and germacrene D was

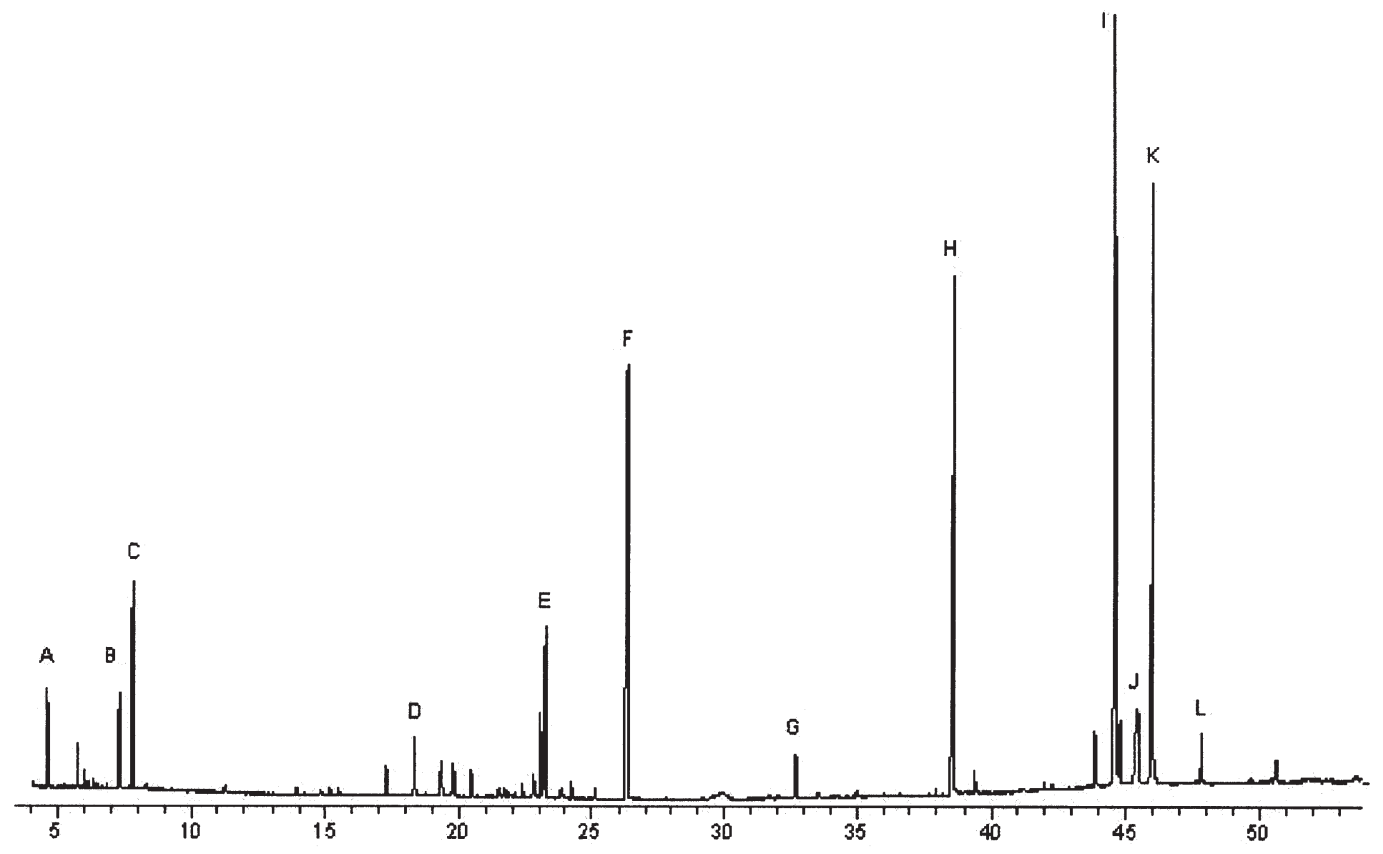

FIG. 2. A, $\alpha$-pinene; B, cis-ocimene; C, trans-ocimene; D, $\beta$-elemene; $E$, germacrene $D ; F$, lauric acid methyl ester; $\mathrm{G}$, myristic acid methyl ester; $\mathrm{H}$, palmitic acid methyl ester; I, oleic acid methyl ester; J, gadoleic acid methyl ester; $\mathrm{K}$, linoleic acid methyl ester; L, linolenic acid methyl ester. 
the most abundant sesquiterpene (Fig. 2). These major components, among others, were detected by GC analysis of the FAME and were soluble in the same solvent as the FAME in "one-pot" transesterification.

Although the aroma conferred by these volatile components is usually described as pleasant, it is too strong to use laurel oil as a food seasoning.

Other components. The MF obtained by the method described in the Experimental Procedures section consisted mainly of two sesquiterpene lactones, costunolide and dehydrocostuslactone. These were isolated by column chromatography and identified by FTIR, MS, and NMR. The yields observed by isolation of these compounds were 3.4 and $1.7 \%$, respectively, results that perfectly matched those obtained by quantitative ${ }^{13} \mathrm{C}$ NMR analysis of the whole oil (29).

The market price ( $€ 150-180 / \mathrm{L})$ of Madeira laurel oil is consistent with strictly controlled production, which is about 2000 $\mathrm{L}$ per year. This control is justified by the dimensions of the productive area, the poor qualifications of the producers, and the fact that the berries are the preferential food of an endemic species of pigeon that was endangered until recently. The scientific evaluation of its claimed therapeutic applications currently being performed by our group, the application of good agricultural and collection practices, and the recovery of the pigeon population may well contribute to an increase in production, leading to the valorization of this herbal product.

\section{REFERENCES}

1. Alvarez, A.M.R., and M.L.G Rodriguez, Lipids in Pharmaceutical and Cosmetic Preparations, Grasas Aceites 51(1-2):74-96 (2000).

2. Council of Europe, European Pharmacopoeia, 3rd edn., Stationery Office Books/Blackwell, Oxford, United Kingdom, 1996.

3. Darlington, L., and T.W. Stone, Antioxidants and Fatty Acids in the Amelioration of Rheumatoid Arthritis and Related Disorders (review article), Br. J. Nutr. 85:251-269 (2001).

4. Clifford, J.J., J. Drago, A.L. Natoli, J.Y. Wong, A. Kinsella, J.L. Waddington, and K.S. Vaddadi, Essential Fatty Acids Given from Conception Prevent the Physical or Natural Features of Motor Deficit in a Transgenic Model of Huntington's Disease, Neuroscience 109:81-88 (2002).

5. Khan, M.M., D.R. Evans, V. Gunna, R.E. Scheffer, V.V. Parikh, and S.P. Mahadik, Reduced Erythrocyte Membrane Essential Fatty Acids and Increased Lipid Peroxides in Schizophrenia at the Never-Medicated First-Episode of Psychosis and After Years of Treatment with Antipsychotics, Schizophr. Res. 58:1-10 (2002).

6. Eynard, A.R., Potential of Essential Fatty Acids as Natural Therapeutic Products for Human Tumors, Nutrition 19:386-388 (2003).

7. Rivera, D., and C. Obón, The Ethnopharmacology of Madeira and Porto Santo Islands, a Review, J. Pharmacol. 46:73-93 (1995).

8. Afifi, F.U., E. Khalil, S.O. Tamimi, and A. Disi, Evaluation of the Gastroprotective Effect of Laurus nobilis Seeds on Ethanol Induced Gastric Ulcer in Rats, J. Ethnopharmacol. 58:9-14 (1997).

9. Matsuda, H., H. Shimoda, K. Ninomiya, and M. Yoshikawa, Inhibitory Mechanism of Costunolide, a Sesquiterpene Lactone Isolated from Laurus nobilis, on Blood-Ethanol Elevation in Rats: Involvement of Inhibition of Gastric Emptying and Increase in Gastric Juice Secretion, Alcohol Alcohol. 37:121-127 (2002).

10. Hokwerda, H., R. Bos, D.H.H. Tattje, and T.M. Malingre, Composition of the Essential Oils of Laurus nobilis, L. nobilis var. angustifolia, and Laurus azorica, Planta Med. 44:116-119 (1982).
11. Medeiros, J.M.R., M. Macedo, J.P. Constancia, C. Nguyen, G. Cunningham, and D.H. Miles, Antithrombin Activity of Medicinal Plants of the Azores, J. Ethnopharmacol. 72:157-165 (2000).

12. Pedro, L.G., P.A.G. Santos, J.A. da Silva, A.C. Figueiredo, J.C. Barroso, S.G. Deans, A. Looman, and J.J.C. Scheffer, Essential Oils from Azorean Laurus azorica, Phytochemistry 57:245-250 (2001).

13. Pino, J.A., P. Fernandes, R. Marbot, and S.S. Fontinha, Chemical Composition of Leaf Oil of Laurus azorica (Seub.) Franco var. longifolia (O. Kuntze) Kunk. from Madeira, J. Essent. Oil Res. 16:22-23 (2004).

14. Castilho, P.C., M.C. Costa, A. Rodrigues, P.C. Branco, and M. Costa, Characterization of Triacylglycerols in Madeira Laurel Oil by HPLC-Atmospheric Pressure Chemical Ionization-MS, J. Am. Oil Chem. Soc. 81:913-919 (2004).

15. AOAC, Official Methods of Analysis, 15th edn., Association of Official Analytical Chemists, Arlington, VA, 1990, Method 969.18: 1990.

16. European Economic Community (EEC), Commission Regulation (EEC) No. 2568/91 on the Characteristics of Olive Oil and OliveResidue Oil and on the Relevant Methods of Analysis, Official Journal L248:1 (1991).

17. European Economic Community (EEC), Commission Regulation (EEC) No. 1429/92 Amending Regulation 2568/91 on the Characteristics of Olive Oil and Olive-Residue Oil and on the Relevant Methods of Analysis, Official Journal L199:17 (1992).

18. European Economic Community (EEC), Commission Regulation (EEC) No. 183/93 Amending Regulation 2568/91 on the Characteristics of Olive Oil and Olive-Residue Oil and on the Relevant Methods of Analysis, Official Journal L22:58 (1993).

19. European Community (EC), Commission Regulation (EC) No. 656/95 Amending Regulation 2568/91 on the Characteristics of Olive Oil and Olive-Residue Oil and on the Relevant Methods of Analysis, Official Journal L69:1 (1995).

20. Papaseit, T.J., The Colour of Extra Virgin Olive Oil: A Characteristic of Quality, Grasas Aceites 37:204-206 (1986).

21. Rudan Tasic, D., and C. Lofutar, Characteristics of Vegetable Oils of Some Slovene Manufacturers, Acta Chim. Slov. 46:511-521 (1999).

22. Garnier, G., L. Bézanger-Beauquesne, and G. Debraux, Ressources médicinales de la flore française, Vol. 1, Vigot Freres Éditeurs, Paris, 1961.

23. Hafizoglu, H., and M. Reunanen, The Components of Turkish Laurus nobilis with Special Reference to Laurel Berry Fat, Fett Wiss. Technol. 95:304-308 (1993).

24. Frega, N., L.S. Conte, G. Lercker, and P. Capella, Composition of Drupes of Laurus nobilis, Riv. Ital. Sostanze Grasse 59:329-334 (1982).

25. Aparicio, R., and R. Aparicio-Ruýz, Authentication of Vegetable Oils by Chromatographic Techniques, J. Chromatogr. A 881:93-104 (2000).

26. Schultz, H., B. Schader, R. Quilitzsch, and B. Steuer, Quantitative Analysis of Various Citrous Oils by ATR/FT-IR and NIR-FT Raman Spectroscopy, Appl. Spectrosc. 56:117-124 (2002).

27. Verleyen, T., M. Forcades, R. Verhe, K. Dewettinck, A. Huyghebaert, and W. de Greyt, Analysis of Free and Esterified Sterols in Vegetable Oils, J. Am. Oil Chem. Soc. 79:117-122 (2002).

28. Bianchi, G., Plant Waxes, in Waxes: Chemistry, Molecular Biology and Functions, edited by R.J. Hamilton, Oily Press, Dundee, Scotland, 1995.

29. Ferrari, B., P.C. Castilho, F. Tomi, A.I. Rodrigues, M.C. Costa, and J. Casanova, Direct Identification and Quantitative Determination of Costunolide and Dehydrocostuslactone in Laurus novocanariensis Fixed Oil Using ${ }^{13} \mathrm{C}-\mathrm{NMR}$ Spectroscopy, Phytochem. Anal. 16:104-107 (2005).

[Received May 5, 2005; accepted September 21, 2005] 